\title{
Copper-mediated 1,4-Conjugate Addition of Boronic Acids and Indoles to Vinylidenebisphosphonate leading to gem- Bisphosphonates as Potential Antiresorption Bone Drugs
}

\author{
Andrea Chiminazzo, Laura Sperni, Martina Damuzzo, Giorgio Strukul, and \\ Alessandro Scarso ${ }^{*[a]}$
}

A wide range of gem-bisphosphonate tetraethyl esters as precursors for bisphosphonic acids, which are potent inhibitors of bone resorption, bearing alkyl, aryl, and indole substituents in the $\beta$ position were prepared through the $\mathrm{Cu}^{\prime \prime}$-catalyzed 1,4 conjugate addition of boronic acids and indoles to vinylidenebisphosphonate tetraethyl ester.

\section{Introduction}

In 2011, gem-bisphosphonates (BPs, Scheme 1) celebrated 40 years of application in medicinal chemistry $;^{[1]}$ however, the correlation between their chemical structures and biological activities is still a highly debated topic. ${ }^{[2,3]}$ Because of their structural similarity with pyrophosphate, a major constituent of hydroxyapatite present in the mineral portion of bones, BPs ensure specific bone targeting ${ }^{[4]}$ and are widely used as drugs for the treatment of bone disorders such as hypocalcemia and osteoporosis. Bone matrix is constantly formed by osteoblasts and degraded by osteoclasts, and both biological activities are regulated to maintain the equilibrium of calcium in the skeleton (calcium homeostasis).

New studies demonstrated the cellular activity of BPs acting as potent inhibitors of specific enzymes such as farnesyl diphosphate synthase, geranylgeranyl diphosphate synthase, ${ }^{[5,6]}$ and others ${ }^{[7]}$ present in osteoclast metabolism. The inhibition of these enzymes translates into osteoclast inactivation and apoptosis. The presence of a hydroxyl group in the $R^{1}$ position enhances the affinity for hydroxyapatite, and $N$ residues on $R^{2}$, such as alendronic acid and zoledronic acid (Scheme 1), demonstrate good performance in terms of antiresorptive efficien$c y$, targeting the aforementioned enzymes. N-containing BPs can be obtained with various functional groups. Moreover, the development of asymmetric synthesis of $\mathrm{N}$-containing BPs and the study of the toxicity and anti-osteoclast activity of single enantiomers are still important goals. More lipophilic BPs with no $\mathrm{OH}$ group in the $\mathrm{R}^{1}$ position and with cationic residues with a long alkyl chain in the $R^{2}$ position are extremely potent in the inhibition of the osteoclast activity, targeting both enzymes; ${ }^{[5]}$ this finding indicates that BPs are promising candidates for anticancer, ${ }^{[8]}$ antibacterial, and antimalarial drugs. ${ }^{[9]}$

[a] A. Chiminazzo, L. Sperni, M. Damuzzo, Prof. G. Strukul, Dr. A. Scarso Dipartimento di Scienze Molecolari e Nanosistemi

Università Ca' Foscari di Venezia

Dorsoduro 2137, 30123 Venezia (Italy)

E-mail:alesca@unive.it

Supporting information for this article is available on the WWW under http://dx.doi.org/10.1002/cctc.201402346.
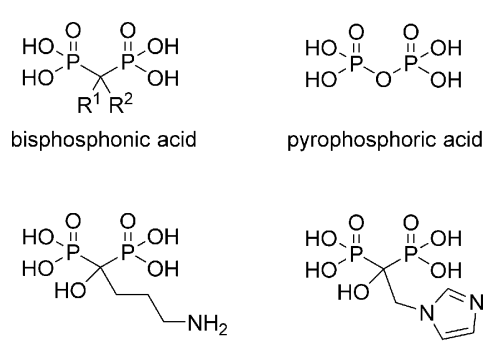

alendronic acid zoledronic acid

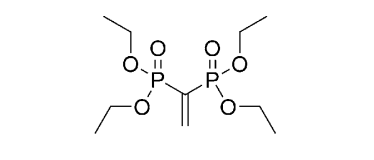

vinylidenebisphosphonate ethyl ester

Scheme 1. Chemical structures of bisphosphonates, pyrophosphoric acid, alendronic acid, zoledronic acid, and VBP.

The synthesis of an increasingly wide range of BPs is highly desirable. BPs with $\mathrm{R}^{1}=\mathrm{OH}$ are prepared starting from an acyl chloride $^{[10]}$ or a carboxylic acid ${ }^{[11]}$ usually under harsh conditions or, as recently disclosed, under milder conditions using the same reagents catecholborane and trimethylsilyl phosphite. ${ }^{[12]}$

The conjugate addition of nucleophiles to vinylidenbisphosphonate tetraethyl ester $(\mathrm{VBP})^{[13]}$ is instead the most common synthetic strategy used to synthesize BPs with $\mathrm{R}^{1}=\mathrm{H}$. By using this method, BPs bearing heterocycles, ${ }^{[14]}$ steroid conjugates, ${ }^{[15]}$ or other functional groups in the $\beta$ position have been prepared. VBP acts efficiently as a dienophile that undergoes Diels-Alder reactions with dienes ${ }^{[16]}$ and nitrones ${ }^{[17]}$ and provides cyclic carbon- and isoxazolidine-containing BPs, respectively. Other BP-based systems have been prepared by using different synthetic approaches, which produce new amino-, ${ }^{[18]}$ azido- ${ }^{[19]} \mathrm{Pt}^{\prime \prime}$-containing ${ }^{[20]} \mathrm{BPs}$ and many others, ${ }^{[21]}$ as along with trisphosphonates. ${ }^{[22]}$

Chiral BPs bearing stereocenters in the $\gamma$ position have been obtained through asymmetric organocatalysis with VBP and carbonyl compounds. ${ }^{[23]}$ These BPs have also been prepared with chiral $\mathrm{Cu}^{\prime}$ diamine complexes ${ }^{[24]}$ in the reaction between prochiral VBPs and azomethine ylide with excellent diastereoselectivity and enantioselectivity. 
Herein, we described the synthesis of a wide range of $\beta$-arylsubstituted $B P$ with $\mathrm{R}^{1}=\mathrm{H}$ through a highly versatile $\mathrm{Cu}^{\text {"I-cata- }}$ lyzed conjugate addition of aryl boronic acids and indoles to VBP.

The conjugate addition of boronic acids ${ }^{[25]}$ to electron-poor alkenes can be catalyzed efficiently by $\mathrm{Pd}^{11[26]}$ and $\mathrm{Rh}^{1[27]}$ species. The latter metal catalyzed the synthesis of a wide range of $\beta$ substituted functional groups such as acrylic acids, ${ }^{[28]}$ enesulfonamides, ${ }^{[29]}$ and many others. ${ }^{[30]}$ This class of catalytic reactions well tolerates the presence of water as described in the addition of boronic acids to acrylic acid ${ }^{[28]}$ and substituted acrylic esters, ${ }^{[31]}$ with positive effects on the asymmetric version of the reaction such as in the addition to enones. ${ }^{[32,33]}$ In contrast, in the addition of boronic reagents to alkenylphosphonates, ${ }^{[34]}$ the presence of a large amount of water as a cosolvent was detrimental and triarylcycloboroxane derivatives (arylboroxines) were used to ensure high yields.

\section{Results and Discussion}

\section{Boronic acids and esters conjugate addition to VBP}

The reaction between phenylboronic acid and VBP was investigated with different metal precursors in the presence of $10 \%$ mol catalyst loading, and it was found that Pd" precursors as well as $\mathrm{Zn}(\mathrm{OTf})_{2}(\mathrm{OTf}=$ trifluoromethanesulfonate) and Cul were not effective in the reaction under different experimental conditions (Table 1, entries 1-5).

In contrast, $\mathrm{Cu}(\mathrm{OTf})_{2}{ }^{[35]}$ demonstrated moderate catalytic activity and provided the corresponding BP product in 40 and $44 \%$ yield at 70 and $85^{\circ} \mathrm{C}$ with 1,2-dichloroethane (DCE) (Table 1, entries 6 and 9). A higher yield of the BP product can be obtained by increasing the amount of phenylboronic acid to 5 equiv. ( $75 \%$ yield; Table 1 , entry 7 ), whereas by maintaining the same amount of phenylboronic acid and by decreasing the catalyst loading to $2 \% \mathrm{~mol}$, the yield decreased to $45 \%$ (Table 1, entry 8 ). A rapid solvent screening revealed that the reaction could be performed in a water/1,4-dioxane mixture (9:1) with a small increase in yield (47\%; Table 1 entry 10), whereas a good yield of the BP product was obtained with an apolar solvent such as toluene ( $90 \%$ yield; Table 1, entry 11 ). A slight increase in yield was observed (up to $94 \%$ ) with a higher amount of phenylboronic acid ( 5 equiv.), which allowed us to decrease the $\mathrm{Cu}(\mathrm{OTf})_{2}$ amount to $2 \%$ mol (Table 1 , entries 12 and 13).

The optimized catalytic system was used for the synthesis of a wide range of boronic acids with different steric and electronic properties as well as bearing different secondary functional groups (Table 2). Usually poorly reactive alkyl boronic acids provided BP products in modest to moderate yields (Table 2, entries 1-3), whereas aromatic boronic acids provided higher yields. The reaction with aryl boronic acids bearing electron-donating groups, such as p-tert-butyl, $p$-methoxy, bisalkoxy, and dimethylamino, gave BP products in good yields (Table 2, entries 4-8). Boronic acids bearing nitro or halogen atoms led to a slight decrease in product formation, even for an ortho-substituted boronic acid (Table 2, entries 9-11). The

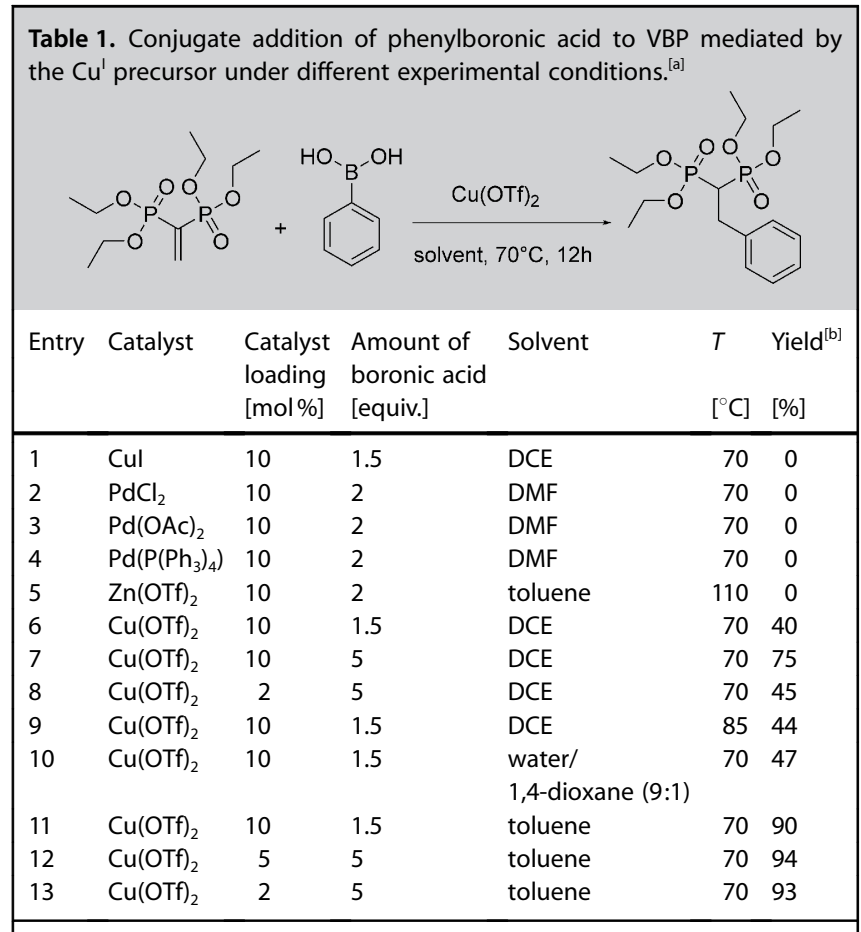

[a] Reaction conditions: $0.33 \mathrm{mmol}$ of $\mathrm{VBP}, 0.5 \mathrm{mmol}$ of phenylboronic acid, $2 \mathrm{~mL}$ of the solvent, $t=18 \mathrm{~h}$; [b] Isolated yield.

reaction well tolerates the presence of other functional groups on boronic acids such as the aldehyde moiety (Table 2, entry 12).

Naphthyl boronic acids bearing alkyl, alkoxy, or halogenated substituents provided the corresponding BP products in good to excellent yields, even if the substituents are close to the boronic moiety, which thus generated steric effects (Table 2, entries 13-19). Heteroaromatic boronic acids did not perform well in the reaction, such as in the cases of pyridine-, quinoline-, isoquinoline-containing substrates. In contrast, the electron-rich aminopyridine boronic ester (Table 2, entry 20) was found to be a suitable substrate. Thiophene- and benzothiophene-containing boronic acids demonstrated optimal to good conversion to the corresponding BPs (Table 2, entries 21 and 22), whereas furane-based boronic acids did not work at all. A ditopic substrate such as indole-5-boronic acid preferentially led to the formation of the corresponding 5-substituted indole (Table 2, entry 23) but no formation of the 3-substituted indole product, as reported later for typical indole substrates. The reaction also proceeds smoothly with bis-boronic acids such as in the case of the substrate reported in Table 2 (entry 24), which in the presence of 3 equiv. of VBP provided the doubly substituted BP in $71 \%$ yield.

We recently reported the general addition reaction between boronic acids and VBP with $4.8 \%$ mol of dimeric $\mathrm{Rh}^{1}$ in the water/1,4-dioxane mixture $(9: 1)$ at $110^{\circ} \mathrm{C}$, which gave BPs in extremely good yields. ${ }^{[36]}$ As compared with the above-mentioned system, the $\mathrm{Cu}(\mathrm{OTf})_{2}$-based system described herein used a comparable amount of a much less expensive and nonhazardous metal catalyst under milder experimental conditions, which gave products in only slightly lower yields with 


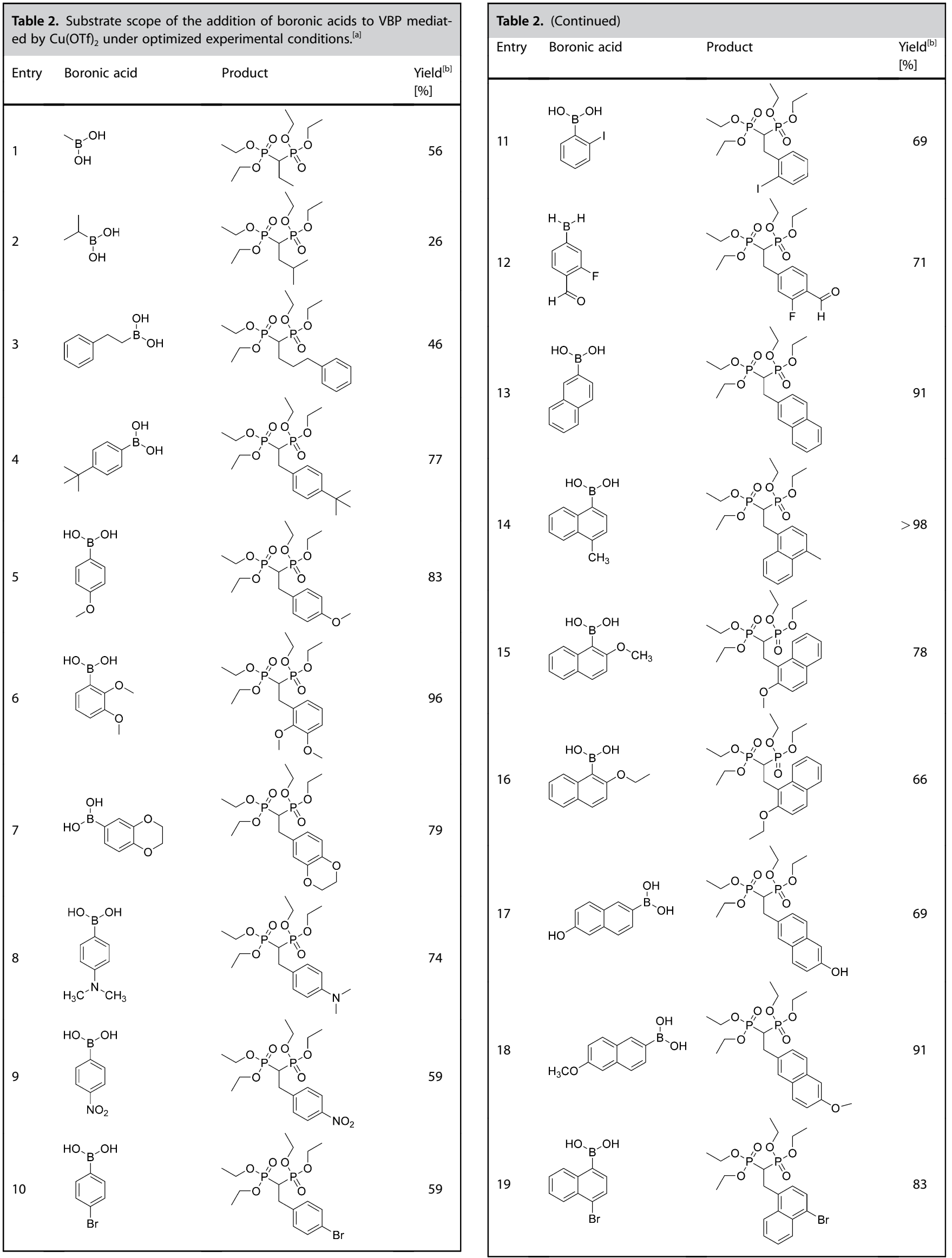




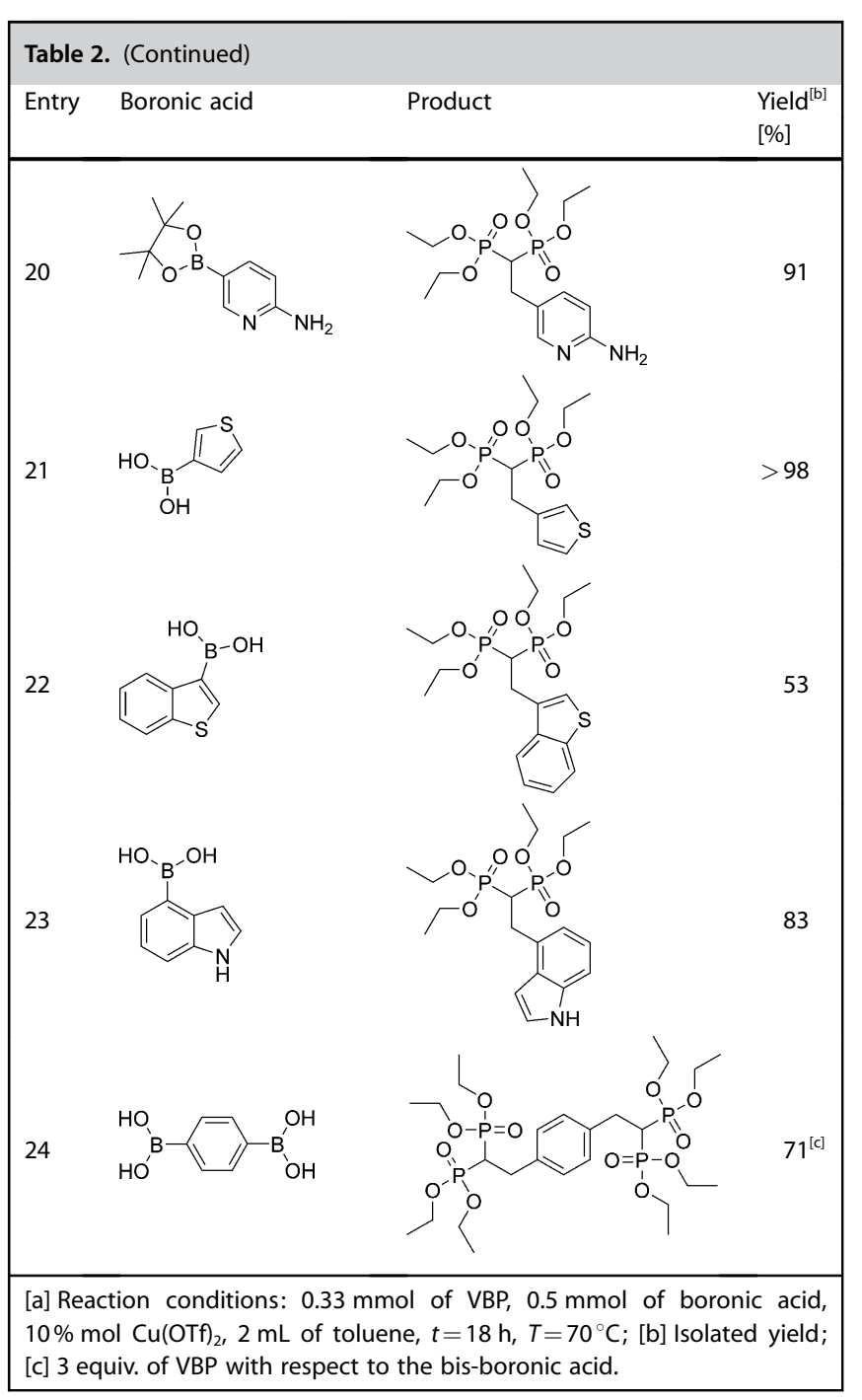

some boronic acids and in higher yields with aliphatic boronic acids. The $\mathrm{Cu}^{\prime \prime}$-mediated reaction could be scaled up: the reaction between (4-methyl-1-naphthyl)boronic acid and VBP was repeated with $3 \mathrm{mmol}$ of $\mathrm{VBP}$, which gave the corresponding addition product in $97 \%$ isolated yield. Several attempts were made to tackle the asymmetric version of the reaction by investigating the addition of phenylboronic acid to tetraethyl (2phenylethene-1,1-diyl)bis(phosphonate) under Cu"-optimized catalytic conditions. However, the desired product was not obtained even with use of the highly electrophilic substrate tetraethyl [2-(4-nitrophenyl)ethene-1,1-diyl]bis(phosphonate) in the presence of chiral bis(oxazoline) ligands (+)-2,2'-isopropylidenebis[(4R)-4-benzyl-2-oxazoline] and 2,6-bis[(4S)-(-)-isopropyl-2-oxazolin-2-yl]pyridine (Scheme S1).

\section{Friedel-Crafts reaction between indoles and VBP}

3-Substituted indoles are important structures that are widely distributed in many important natural products ${ }^{[37]}$ as well as in pharmacophores demonstrating many biological activities. ${ }^{[38]}$ The Cu"-based catalysts can efficiently promote the FriedelCrafts reaction of indoles with alkylidene malonates or nitroal- kenes in the enantioselective way. ${ }^{[39-42]}$ Although the reaction between indoles and VBP has been investigated under Brønsted basic and acidic conditions with emphasis on the regioselectivity of the reaction, ${ }^{[43]}$ no examples of the reaction involving metal catalysis can be found in the literature.

Copper precursors were therefore tested in the FriedelCrafts reaction between indole and VBP, and it was found that $\mathrm{Cu}(\mathrm{OTf})_{2}$ in DCE led to the addition reaction, forming the desired 3-substituted indole derivative in increasing amounts (up to $97 \%$ yield) as a function of the catalyst loading (Table 3, entries 3-5). In contrast, other copper catalysts with different anions and oxidation states, such as Cul, or other metal complexes such as $\mathrm{PdCl}_{2}$ were found to be ineffective in promoting the reaction (Table 3, entries 1 and 2). The reaction did not gave the product in good yield in toluene (Table 3, entry 6); however, in water with sodium dodecyl sulfate (SDS) used as a surfactant to improve substrate solubilization, the desired product was obtained in $94 \%$ yield, which was comparable to that observed in DCE (Table 3, entry 5). The use of water as a reaction medium has also been confirmed for other FriedelCrafts-type conjugate additions of indoles by using a Lewis acid-surfactant combined catalyst in water, ${ }^{[44]}$ however, this is the first example, to our knowledge, in which this approach is applied to synthesize BPs. The possibility to use either an organic solvent or a micellar medium in this reaction was also investigated.

For the reaction in DCE, the optimized catalytic system was used with a wide range of indoles with different electronic and steric properties (Table 4). The reaction is intrinsically sensitive to the electronic properties of the indole used. ${ }^{[45]}$ Thus, indoles bearing electron-donating substituents such as 1-methylindole and 1,2-dimethylindole provided the corresponding addition products in high yield (Table 4, entries 1 and 2). The electronrich substrate 5-methoxyindole provided the corresponding BP addition product in $90 \%$ yield, whereas the presence of an extra trifluoromethyl moiety in position 6 of the same structure drastically reduced the yield to $39 \%$ and a similar effect was

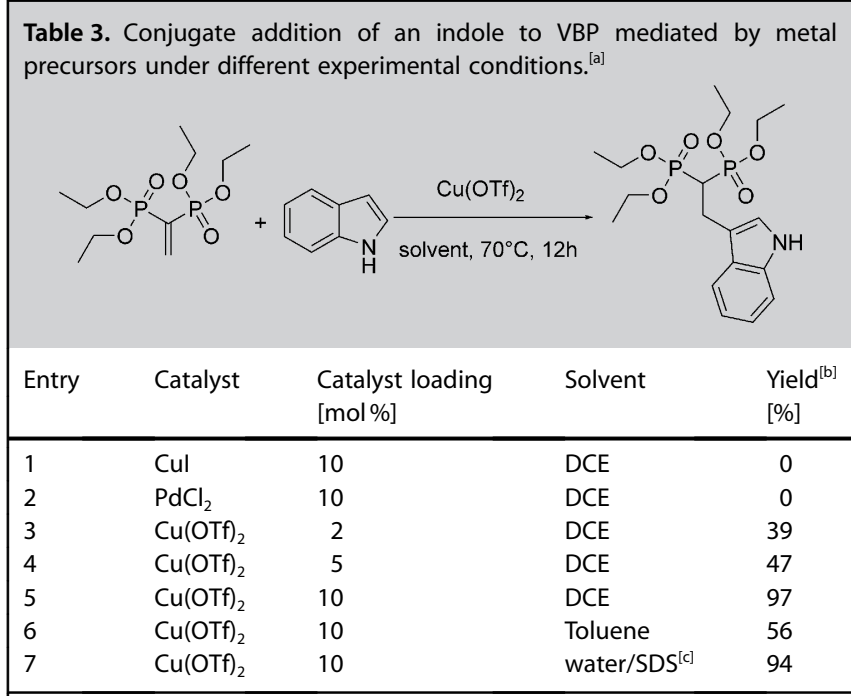

[a] Reaction conditions: $0.3 \mathrm{mmol}$ of VBP, $0.5 \mathrm{mmol}$ of the indole, $2 \mathrm{~mL}$ of the solvent, $t=12 \mathrm{~h}, T=70^{\circ} \mathrm{C}$; [b] Isolated yield; [c] [SDS] $=100 \mathrm{~mm}$. 
observed with 6-bromo-7-methyl-indole (Table 4, entries 3-5). Notably, electron-poor substrates such as the ester 5-(carboxymethyl)indole and the corresponding free acid 5-carboxyindole led to the formation of BP products in moderate yields (Table 4, entries 6 and 7) whereas 5-carboxamide indole was found to be completely inactive. With the above-mentioned indole substrates, the reaction in water/SDS led to in most cases comparable and in few cases better product formation, which was related to the ability of the micellar medium to dissolve the reagents and to place them close to the metal catalyst present as a countercation on the surface of the anionic micelles.

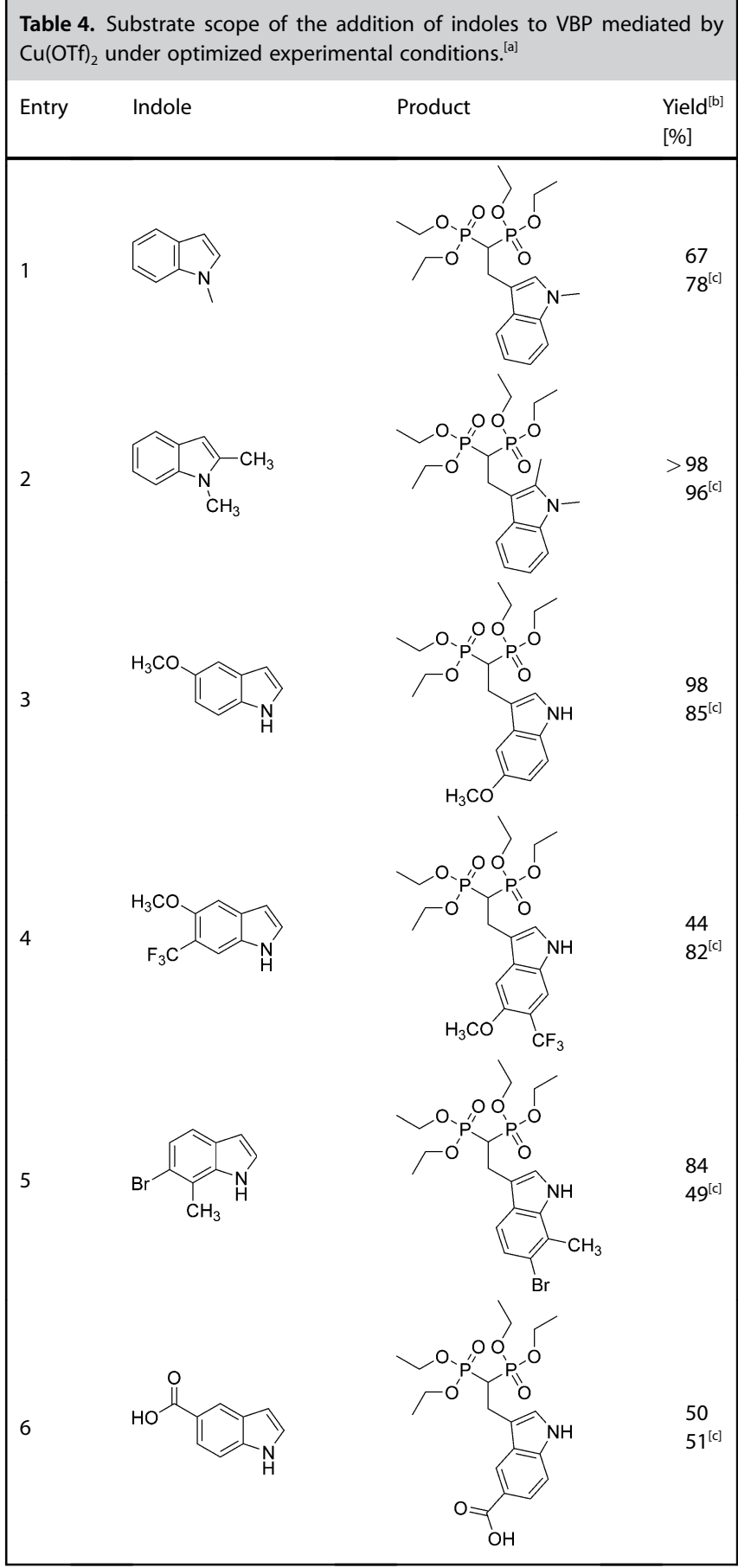

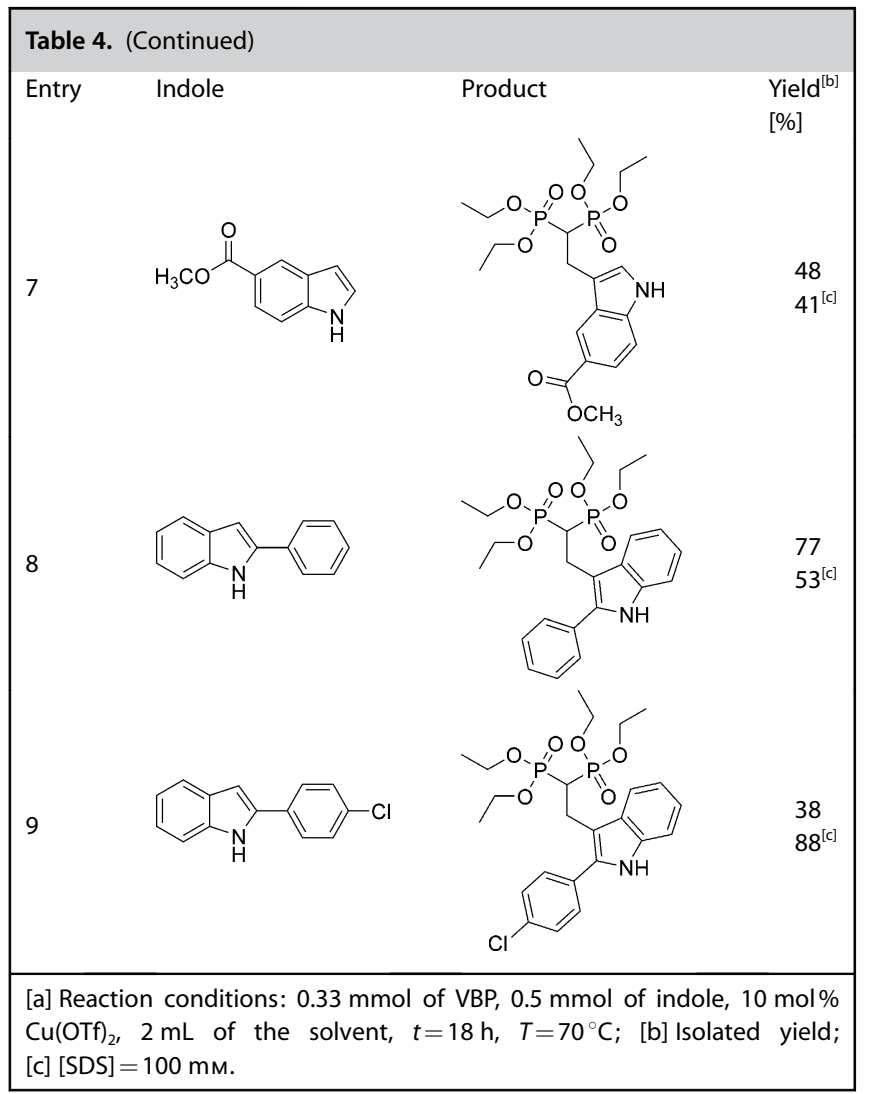

Indoles with substituents in position 2 demonstrated moderate to good activity: the reaction with 2-phenylindole, which is an extremely important structure in medicinal chemistry, ${ }^{[46]}$ led to the formation of the corresponding BP derivative in $77 \%$ yield in DCE and $53 \%$ yield in water/SDS (Table 4, entry 8 ). A similar reagent bearing a $p-\mathrm{Cl}$ residue led to the formation of the product in moderate yield, whereas a substrate bearing a 2- $\left(\mathrm{CH}_{2} \mathrm{OH}\right)$ indole, even though more electron rich than indole, did not lead to product formation. For these substrates, the use of water/SDS as a reaction medium was beneficial for the 2-p-Cl-phenyl-substituted indole, which led to the formation of the corresponding BP product in $88 \%$ yield (Table 4 , entry 9).

The reaction could easily be scaled up by using $3 \mathrm{mmol}$ of VBP with 1.5 equiv. of 1,2-dimethylindole in the presence of $10 \mathrm{~mol} \% \mathrm{Cu}(\mathrm{OTf})_{2}$ in $\mathrm{DCE}$, which led to the formation of the corresponding isolated addition product in $94 \%$ yield.

Several attempts were made to investigate the asymmetric version of the indole addition by performing the reaction using two prochiral aromatic bisphosphonates ${ }^{[24]}$ with different electronic properties under previously optimized catalytic conditions (Scheme S1). Unfortunately, no evidence of product formation was obtained and in both cases, only the unconverted prochiral bisphosphonate reagent was recovered.

Selected new BP products containing indole derivatives were subjected to subsequent deprotection of the phosphonate ester moiety by treatment with trimethylbromosilane ${ }^{[47]}$ followed by hydrolysis with the water/methanol solution (9:1). The corresponding bisphosphonic acids (Table 5) were isolated 


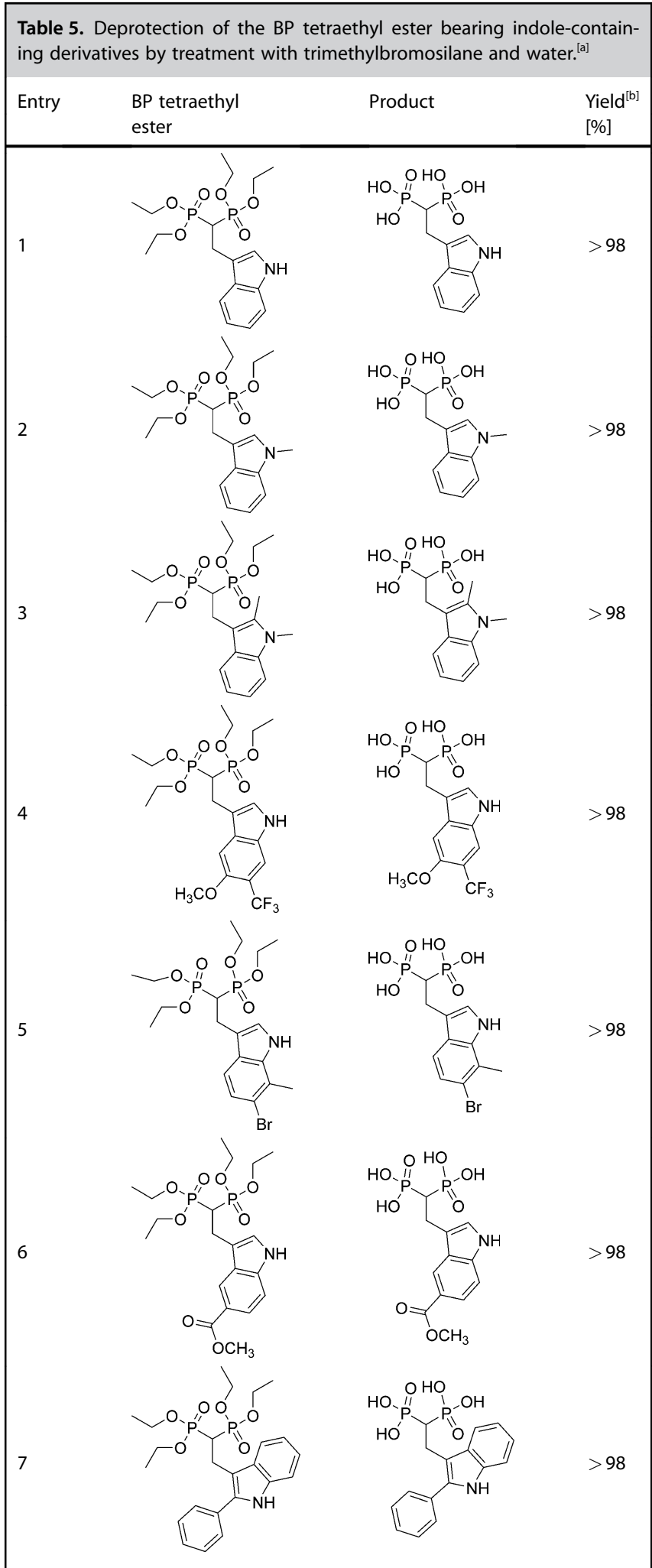

in good yields and were characterized by ${ }^{1} \mathrm{H}$ and ${ }^{31} \mathrm{P}$ NMR spectroscopy in $\mathrm{D}_{2} \mathrm{O}$. Not all indole $\mathrm{BP}$ esters led to the formation of the corresponding bisphosphonic acids owing to side reactions involving the indole moiety, which, in some cases, were released in the solution owing to retro-Michael addition side reactions.

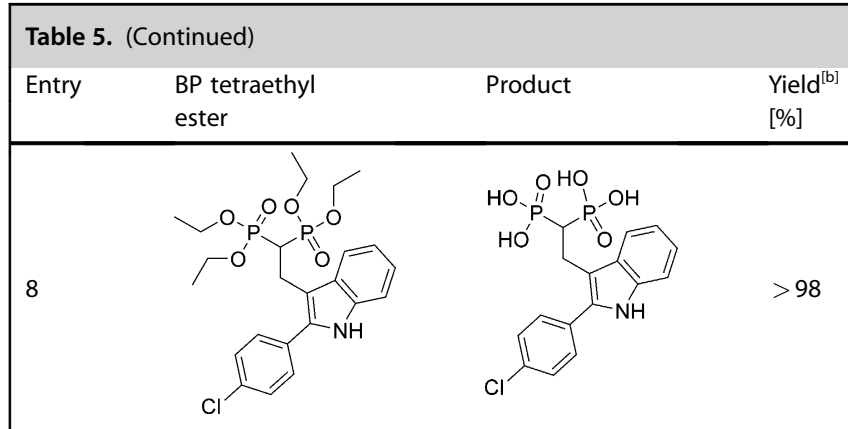

[a] Reaction conditions: $0.2 \mathrm{mmol}$ of BP tetraethyl ester, $2.4 \mathrm{mmol}$ of trimethylsilyl bromide, $t=18 \mathrm{~h}$, room temperature; then water, $t=4 \mathrm{~h}$, room temperature; [b] Isolated yield.

\section{Conclusions}

Herein, we presented a straightforward synthesis of gem-bisphosphonates (BPs) lacking the gem-OH group and bearing alkyl, aryl, and indolyl substituents in the $\beta$ position through the $\mathrm{Cu}^{\prime \prime}$-mediated conjugate addition of alkyl and aryl boronic acids and indoles to vinylidenbisphosphonate tetraethyl ester. The synthesis can be scaled up to $3 \mathrm{mmol}$ without any significant changes in experimental conditions and yields. Although the addition of boronic acids proceeds much smoothly in the noncoordinating solvent toluene, the addition of indoles can be performed either in 1,2-dichloroethane or in water with sodium dodecyl sulfate under micellar conditions, leading to comparable efficiency. The activation of both the indole addition and the boronic acid addition to BPs mediated by $\mathrm{Cu}^{\prime \prime}$ is likely due to the increased electrophilic character of BPs because of its coordination to the metal center. It is also likely that $\mathrm{Cu}^{\text {II }}$ favors the boronic acid addition through transmetalation/insertion as recently disclosed for the 1,4-addition of organoboronates to alkylidene cyanoacetates ${ }^{[48]}$ and for the addition of boronic acids to alkynoates. ${ }^{[49]}$ However, the asymmetric version of both reactions was found to be impossible with Cu", probably because of intrinsic steric hindrance imparted by the two closely connected phosphonate moieties. This efficient and versatile synthesis of BPs enabled the preparation of several BP tetraethyl esters that were transformed into the corresponding bisphosphonic acids that are currently under investigation to assess their toxicity and antiresorption properties in the inhibition of the osteoclast activity.

\section{Experimental Section}

The experimental details can be found in the Supporting Information.

\section{Acknowledgements}

We acknowledge financial support from the MIUR (PRIN project 2008), the Universitá Ca' Foscari di Venezia, and the Consorzio Interuniversitario Nazionale per la Scienza e Tecnologia dei Materiali. 
Keywords: bisphosphonates • boronic acid · copper • indoles Michael addition

[1] R. Graham, G. Russell, Bone 2011, 49, 2-19.

[2] F. H. Ebetino, A.-M. L. Hogan, S. Sun, M. K. Tsoumpra, X. Duan, J. T. Triffitt, A. A. Kwaasi, J. E. Dunford, B. L. Barnett, U. Oppermann, M. W. Lundy, A. Boyde, B. A. Kashemirov, C. E. McKenna, R. G. G. Russell, Bone 2011, 49, 20-33.

[3] M. J. Rogers, J. C. Crockett, F. P. Coxon, J. Mönkkönen, Bone 2011, 49, $34-41$.

[4] S. Zhang, G. Gangal, H. Uludağ, Chem. Soc. Rev. 2007, 36, 507-531.

[5] Y. Zhang, R. Cao, F. Yin, M. P. Hudock, R.-T. Guo, K. Krysiak, S. Mukherjee, Y.-G. Gao, H. Robinson, Y. Song, J. H. No, K. Bergan, A. Leon, L. Cass, A Goddard, T.-K. Chang, F.-Y. Lin, E. Van Beek, S. Papapoulos, A. H.-J. Wang T. Kubo, M. Ochi, D. Mukkamala, E. Oldfield, J. Am. Chem. Soc. 2009 $131,5153-5162$.

[6] A. J. Wiemer, J. S. Yu, L. W. Shull, R. J. Barney, B. M. Wasko, K. M. Lamb, R. J. Hohl, D. F. Wiemer, Bioorg. Med. Chem. 2008, 16, 3652-3660.

[7] A. G. Roth, D. Drescher, Y. Yang, S. Redmer, S. Uhlig, C. Arenz, Angew. Chem. Int. Ed. 2009, 48, 7560-7563; Angew. Chem. 2009, 121, $7697-$ 7700 .

[8] Y. Zhang, R. Cao, F. Yin, F.-Y. Lin, H. Wang, K. Krysiak, J.-H. No, D. Mukkamala, K. Houlihan, J. Li, C. T. Morita, E. Oldfield, Angew. Chem. Int. Ed. 2010, 49, 1136-1138; Angew. Chem. 2010, 122, 1154- 1156.

[9] J. H. No, F. de Macedo Dossin, Y. Zhang, Y.-L. liu, W. Zhu, X. Feng, J. A Yoo, E. Lee, K. Wang, R. Hui, L. H. Freitas-Junior, E. Oldfield, Proc. Natl. Acad. Sci. USA 2012, 109, 4058-4063.

[10] R. L. McConnell, H. W. Coower, J. Am. Chem. Soc. 1956, 78, 4450-4452.

[11] G. R. Kieczykowski, R. B. Jobson, D. G. Mellilo, D. F. Reinhold, V. J. Grenda, I. Shinkai, J. Org. Chem. 1995, 60, 8310-8312.

[12] M. Egorov, S. Aoun, M. Padrines, F. Redini, D. Heymann, J. Lebreton, M. Mathé-Allainmat, Eur. J. Org. Chem. 2011, 7148-7154.

[13] R. A. Nugent, M. Murphy, S. T. Schlachter, C. J. Dunn, R. J. Smith, N. D. Staite, L. A. Galinet, S. K. Shields, D. G. Aspar, K. A. Richard, N. A. Rohloff, J. Med. Chem. 1993, 36, 134-139.

[14] D. Simoni, N. Gebia, F. P. Invidiata, M. Eleopra, P. Marchetti, R. Rondanin R. Baruchello, S. Provera, C. Marchioro, M. Tolomeo, L. Marinelli, V. Limongelli, E. Noveliono, A. Kwaasi, J. Dunford, S. Buccheri, N. Cacamo, F. Dieli, J. Med. Chem. 2008, 51, 6800-6807.

[15] P. C. B. Page, M. J. McKenzie, J. A. Galagher, J. Org. Chem. 2001, 66 $3704-3708$.

[16] R. Ruzziconi, G. Rici, A. Gioiello, H. Couthon-Gourvès, J.-P. Gourvès, J. Org. Chem. 2003, 68, 736-742.

[17] O. Bortolini, I. Mulani, A. De Nino, L. Maiuolo, M. Nardi, B. Russo, S. Avnet, Tetrahedron 2011, 67, 5635-5641.

[18] a) V. Kubíček, J. Kotek, O. Hermann, I. Lukeš, Eur. J. Inorg. Chem. 2007, 333-344; b) E. Dabrowska, A. Burzyńska, A. Mucha, E. Matczak-Jon, W. Sawka-Dobrowolska, Ł. Berlicki, P. Kafarski, J. Organomet. Chem. 2009, 694, 3806-3813.

[19] B. T. Chamberlain, T. G. Upton, B. A. Kashemirov, C. E. McKenna, J. Org. Chem. 2011, 76, 5132-5136.

[20] Z. Xue, M. Lin, J. Zhu, J. Zhang, Y. Li, Z. Guo, Chem. Comun. 2010, 46, $1212-1214$

[21] J.-P. Haelters, H. Couthon-Gouvès, A. Le Goff, G. Simon, B. Corbel, P.-A. Jaffrès, Tetrahedron 2008, 64, 6537-6543.

[22] J. P. Smits, D. F. Wiemer, J. Org. Chem. 2011, 76, 8807-8813.

[23] a) M. T. Barros, A. M. Faísca Phillips, Eur. J. Org. Chem. 2008, 2525-2529; b) S. Sulzer-Mossé, M. Tossot, A. Alexakis, Org. Lett. 2007, 9, 3749-3752 c) S. Sulzer-Mossé, A. Alexakis, J. Mareda, G. Bolot, G. Bernardinelli, Y. Filinchuk, Chem. Eur. J. 2009, 15, 3204-3220; d) M. Capuzzi, D. Perdicchia, K. A. Jørgensen, Chem. Eur. J. 2008, 14, 128-135.

[24] Z.-Y. Xue, Q.-H. Li, H.-Y. Tao, C.-J. Wang, J. Am. Chem. Soc. 2011, 133, $11757-11765$

[25] a) H. J. Edwards, J. D. Hargrave, S. D. Penrose, C. G. Frost, Chem. Soc. Rev 2010, 39, 2093-2105; b) J. F. Teichert, B. L. Feringa, Angew. Chem. Int Ed. 2010, 49, 2486-2528; Angew. Chem. 2010, 122, 2538-2582; c) T. Hayashi, K. Yamasaki, Chem. Rev. 2003, 103, 2829-2844; d) K. Fagnou,
M. Lautens, Chem. Rev. 2003, 103, 169-196; e) T. Hayashi, Synlett 2001 $879-887$

[26] K. Kikushima, J. C. Holder, M. Gatti, B. M. Stoltz, J. Am. Chem. Soc. 2011 133, 6902-6905.

[27] G. Berthon, T. Hayashi in Rhodium- and Palladium-Catalyzed Asymmetric Conjugate Additions, in Catalytic Asymmetric Conjugate Reactions (Ed.: A. Córdova), Wiley-VCH, Weinheim, Germany, 2010.

[28] N. R. Vautravers, B. Breit, Synlett 2011, 17, 2517-2520.

[29] H. Zilaout, A. van den Hogenband, J. de Vries, J. H. M. Lange, J. W. Terpstra, Tetrahedron Lett. 2011, 52, 5934-5939.

[30] Selected examples of the application of boronic acid addition mediated by $\mathrm{Rh}^{\prime}$ : a) enones: M. T. Reetz, D. Moulin, A. Gosberg, Org. Lett. 2001, 3, 4083-4085; b) unsaturated esters: C. J. Chapman, C. G. Frost, Adv. Synth. Catal. 2003, 345, 353-355; c) allyl sulfones: G. C. Tsui, M. Lautens, Angew. Chem. Int. Ed. 2010, 49, 8938-8941; Angew. Chem. 2010, 122 9122-9125; d) allylamines: G. C. Tsui, F. Menard, M. Lautens, Org. Lett. 2010, 12, 2456-2459; e) vinylarenes, G. Pattison, G. Piraux, H. W. Lam, J. Am. Chem. Soc. 2010, 132, 14373-14375; f) alkenylarenes: M. Lautens, M. Yoshida, J. Org. Chem. 2003, 68, 762-769.

[31] K. J. Wadsworth, F. K. Wood, C. J. Chapman, C. G. Frost, Synlett 2004, 11, $2022-2024$.

[32] C.-G. Feng, Z.-Q. Wang, C. Shao, M.-H. Xu, G.-Q. Lin, Org. Lett. 2008, 10, $4101-4104$

[33] Y. Otomaru, T. Senda, T. Hayashi, Org. Lett. 2004, 6, 3357-3359.

[34] T. Hayashi, T. Senda, Y. Takaya, M. Ogasawara, J. Am. Chem. Soc. 1999, $121,11591-11592$.

[35] a) C. Hertweck, Adv. Synth. Catal. 2000, 342, 316-321; b) M. K. Gupta, Synlett 2005, 6, 1044-1045.

[36] G. Bianchini, A. Scarso, A. Chiminazzo, L. Sperni, G. Strukul, Green Chem. 2013, 15, 656-662.

[37] D. Faulkner, Nat. Prod. Rep. 1999, 16, 155.

[38] a) J. H. Wynne, W. M. Stalick, J. Org. Chem. 2002, 67, 5850; b) A. Kumar, S. Sharma, R. A. Maurya, Tetrahedron Lett. 2009, 50, 5937-5940; c) Z.-X Wang, A. J. Kochanowska-Karamyan, M. T. Hamann, Chem. Rev. 2010, 110, 4489-4497; d) R. Contractor, I. J. Samudio, Z. Estrov, D. Harris, J. A. McCubrey, S. H. Safe, M. Andreeff, M. Konopleva, Cancer Res. 2005, 65, 2890

[39] a) J. Zhou, M.-C. Ye, Z.-Z. Huang, Y. Tang, J. Org. Chem. 2004, 69, 13091320; b) J. Zhou, Y. Tang, Chem. Commun. 2004, 432-433; c) H. Y. Kim, S. Kim, K. Oh, Angew. Chem. Int. Ed. 2010, 49, 4476-4478; Angew. Chem. 2010, 122, 4578-4580.

[40] a) Y.-J. Sun, N. Li, Z.-B. Zheng, L. Liu, Y.-B. Yu, Z.-H. Qin, B. Fu, Adv. Synth Catal. 2009, 351, 3113-3117; b) Y.-Y. Zhou, X.-L. Sun, B.-H. Zhu, J.-C. Zheng, J.-L. Zhou, Y. Tang, Synlett 2011, 935-938; c) L. Liu, J. Li, M. Wang, F. Du, Z. Qin, B. Fu, Tetrahedron: Asymmetry 2011, 22, 550-557; d) J. Zhou, Y. Tang, J. Am. Chem. Soc. 2002, 124, 9030-9031.

[41] K. A. Jørgensen, Synthesis 2003, 1117-1125.

[42] a) W. Zhuang, T. Hansen, K. A. Jørgensen, Chem. Commun. 2001, $347-$ 348; b) L. Wen, Q. Shen, X. Wan, L. Lu, J. Org. Chem. 2011, 76, $2282-$ 2285.

[43] H. Couthon-Gourvès, G. Simon, J.-P. Haelters, B. Corbel, Synthesis 2006, $81-88$.

[44] K. Manabe, N. Aoyama, S. Kobayashi, Adv. Synth. Catal. 2001, 343, $174-$ 176.

[45] H. Johansson, T. Bøgeløv Jørgensen, D. E. Gloriam, H. Bräuner-Osborne, D. Sejer Pedersen, RSC Adv. 2013, 3, 945-960.

[46] Electron-poor and/or sterically hindered substrates such as 2-carboxymethyl-indole, 5-chloro-tert-butoxycarbonyl-indole, and acetylindole were all found to be unreactive.

[47] C. E. Mckenna, M. T. Higa, N. H. Cheung, M. C. Mckenna, Tetrahedron Lett. 1977, 18, 155-158.

[48] K. Takatsu, R. Shintani, T. Hayashi, Angew. Chem. Int. Ed. 2011, 50, 5548 5552; Angew. Chem. 2011, 123, 5662-5666.

[49] Y. Yamamoto, N. Kirai, Y. Harada, Chem. Commun. 2008, 2010-2012.

Received: May 16, 2014

Published online on August 19, 2014 